\title{
Research Article International Collaborative Research Possibilities for Environmental Education in Asia
}

\author{
Kimiharu To*, Tzuchau Chang**, Chankook Kim ***, Sun-kyung Lee ****, Ryo Sakurai *****, \\ Sachi Ninomiya-Lim******, Noriko Hata*******, Junko Katayama********, Shinichi Furihata********* \\ Aomori University*, Taiwan Normal University**, Korea National University of Education***, \\ Cheongju National University of Education****, Ritsumeikan University*****, Tokai University******, \\ Tsuru University*******, Istanbul Kultur University********, \\ Tokyo University of Agriculture and Technology********* \\ Accepted on May 28, 2019
}

\begin{abstract}
Taking into account of the both significant growth of higher education in Asia and the infiltration of cosmopolitan viewpoints in environmental education research, our team designed and conducted pilot survey amongst EE researchers of Japan, Korea and Taiwan $(n=51)$ concerning: self-evaluation; methodology; training; themes; education sector levels and interests in and barriers against international collaboration. This paper shares notable trends revealed through the pilot survey and discuss the significance of these in relation to our future, full-scale survey. Toward conducting a larger-scale survey, two aspects should be stressed. First, use of native language is essential to securing greater participants. This would improve the accuracy of meaning sometimes lost through translation and increase the efficiency of completion. More survey participants would enable us to conduct crossnational comparisons, which this study could not. Second, the support from the participating academic societies is crucial not only for executing a full-scale survey but also facilitating opportunities for increasing research skills and capacities international collaboration.
\end{abstract}

Keywords: cross-national study, capacity building, research competencies, research trend

\section{Introduction}

How are Asian researchers doing in global knowledge production especially in the area of environmental education (hereinafter EE)? Approximately a decade ago, William Scott, the founding editor of Environmental Education Research, called for "greater openness to new cultures" (Scott 2009, p.155) as one of the critical directions for EE research for the next 30 years. Today, this kind of cosmopolitan viewpoint has been shared amongst various EE researchers. For example, Noel Gough (2013) proposes in his introductory essay titled Thinking Globally in Environmental Education in the International Handbook of Research on Environmental Education, to create such research opportunities for "constructing transcultural spaces in which scholars from different localities collaborate in reframing and decentering their own knowledge traditions and negotiate trust in each other's contributions to their collective work" (p.41).

Taking a glance at Asian contexts, the rapid economic growth amongst Asian countries has led to not only the deterioration of environmental and developmental issues but also greater and more diverse growth of higher education in the region (Yonezawa et al. 2014). Along with those regional networks and cooperation for governing higher education institutions such as ASEAN University Network, Asia Pacific Quality Network, Association of Pacific Rim Universities, and University Mobility in Asia and the Pacific, there are regional networks and initiatives that are specifically related to environmental conservation and education, such as Tripartite Environmental Education Network, Environmental Leadership Initiatives for Asian Sustainability, and Promotion of Sustainability 
in Postgraduate Education and Research Network. What's more, Asia's vibrant condition through regional cultural and political diversity has attracted various intellectual attentions from both inside and outside the region. This is evident in such discourses as environmental philosophy (Callicott et al. 2014), communication studies (Miike 2016), educational philosophy and Education for Sustainable Development (ESD) (Jackson 2017), higher education (Yonezawa et al. 2014), comparative education (Park 2017, Takayama et al. 2017), and cultural studies (Chen 2010). A recently published Special Issue of the Japanese Journal of Environmental Education: EE in Asia (Ninomiya-Lim et al. 2017) shares similar concerns because it aims "to create a platform to share ideas, practices, and theories of $E E$ in the Asian region" (p.1). In spite of the growth of the field of EE and intellectual attention, it is still challenging to assess how those researchers of Asian countries where English is used as a second language are engaging in their research activities that are situated in global knowledge production (Yonezawa et al. 2014, Ninomiya-Lim et al. 2017).

The aspiration of our study originates in the aforementioned Special Issue of the Japanese Journal of Environmental Education: EE in Asia (Ninomiya-Lim et al. 2017). Our team of Japanese, Korean and Taiwanese researchers conducted a cross-national survey examining trends in the research activity, research skills and thematic preferences among environmental educators of three Asian nations, including Japan, Korea and Taiwan. The results will characterize quantitative and qualitative information about the trends amongst EE researchers concerning: self-evaluation; methodology; training; EE themes; education sector levels and interests in and barriers against international collaboration. Such a cross-national survey helps facilitate evidence-based analysis by expanding the empirical base, foster inter and trans-national recommendations, and further stimulate current levels of research practices. Also, surveying ourselves is a crucial step for nurturing the critical reflection, mutual understanding and an ethos of how we are doing our own research practice. However, given the survey is a pilot and may undergo further development reflecting greater sophistication and nuance, we acknowledge the limitations of our small sample size. In response to this limitation, our team is hoping to increase participation and feedback from inside and outside the three nations of Japan, Korea and Taiwan. In other words, our pilot survey was used to redesign and execute a fullscale survey. In this paper, we share notable trends and concerns revealed through the pilot survey and discuss the significance of these in relation to a future comprehensive survey.

\section{Literature review}

Our study is rather situated in meta-research. Several studies deal with meta-research on the field of EE, which they help streamlining our pilot survey. These studies can be divided into the three basic categories, such as comprehensive overview (Sauvé 2005, Dillon and Wals 2006, Reid and Scott 2006, Gough A. 2013), geographically specific review (Erdogan et al. 2009, Stevenson and Evans 2011, Marcinkowski et al. 2013, Nomura 2017, Kim 2017) and survey among researchers (Hesselink et al. 2000, Reunamo and Pipere 2011, Ardoin et al. 2013, McHugh and Byrne 2014, Mielke et al. 2017). Those reviews under the first category provide comprehensive overviews on the field of EE. For example, Annette Gough (2013, p.19) illustrates the diversification of EE research since 1960s, "ranging from positivist to critical to poststructuralist and including indigenous, postcolonial and feminist, among others."

Next, studies focusing on geographical areas mainly conduct literature review within a particular nation-state (Erdogan et al. 2009, Stevenson and Evans 2011, Marcinkowski et al. 2013, Nomura 2017, Kim 2017). For example, Marcinkowski et al. (2013) conducted a series of content analysis to show the research trends among doctoral dissertations published in the United States for the 1971-2000 periods. Erdogan et al. (2009) took a similar approach to show the research trends surrounding K-8 levels education in Turkey. Nomura (2017) reviews the articles published in the Japanese Society of Environmental Education and point out the gap between research in Japan and abroad. Kim (2017) applied the 15 genres of EE practice that Sauve (2005) portrayed to show the diversification of EE research in Korea and stresses that emergence of qualitative research methods and the socially critical perspective among contemporary research.

Third category encompasses those studies that are designed with survey among researchers and professionals (Hesselink et al. 2000, Reunamo and Pipere 2011, Ardoin et al. 2013, Mielke et al. 2017, McHugh and Byrne 2014). Although the number of such a study dealing with EE is quite limited, they provide a set of quantitative and 
qualitative information under particular themes surrounding research activities. One of the most thought-provoking examples in this vein is a survey report ESDebate: International debate on education for sustainable development (Hesselink et al. 2000). A series of online interviews with 50 environmental education experts from 25 different countries exemplified that environmental educators, especially the "experts," are divided over how to respond to the emergence of ESD according to the four different relationships: (1) EE as part of ESD; (2) ESD as part of EE; (3) EE is equal to ESD; and (4) ESD as a stage in the evolution of EE (Hesselink et al. 2000). Similarly, Reunamo and Pipere (2011) conduct survey among researchers of 19 different nations $(n=83)$ to grasp the commonalities and differences in ESD researches toward formulating a model of ESD research orientations. Ardoin et al. (2013) utilized online survey $(\mathrm{n}=86)$ among other data collections such as content analysis and interviews, and they revealed the four emerging thematic trends in EE research.

Besides these studies, other studies, mostly outside the field of EE, use survey approach to uncover practical dimensions of individual researchers, such as limitations, communication skills, and methodologies (Altbach 1996, McHugh and Byrne 2014). One of the well-known studies in this genre is the Carnegie International Survey on the Academic Profession (Altbach 1996). The study offers in-depth analysis of academic freedom, workload, research and teaching requirements among 14 countries, which gave a great influence upon the contemporary higher education policies in many nations (Altbach 1996). McHugh and Byrne (2014) have conducted a survey among health and social care professionals $(\mathrm{n}=1325)$ in Ireland to profile their research activities, skills and trainings needs. Illuminating with the results from the same survey conducted in 2011, their study provides the evidence base for determining more effective financial resource allocations within the health and social care sector in Ireland. These studies help determine our research strategy to apply the pilot survey for obtaining the preparatory knowledge toward executing a full-scale, international survey.

\section{Method}

We developed a web-based pilot survey with the tool SurveyMonkey (www.surveymonkey.com), asking 33 questions about research trends in the areas of international collaboration. The aim of pilot survey is twofold: to illuminate concise trends of how Japanese, Korean and Taiwanese EE professionals are engaging in their research activities; and to clarify terminological issues and logistical aspects for the future development of a comparative survey. Since the 2017 winter, our team has participated in a series of online discussions and conference meetings exchanging ideas for designing a future comparative survey. Based on the feedback and comments, some questions were reformulated and the vocabulary simplified. The scale of measurement ranged from nominal to ordinal. The pilot survey is made and conducted in English. The survey questionnaire consisted of 4 different thematic sections concerning self-evaluations, methodologies, training areas, research themes, levels, and interests in and barriers against internationalization toward enhancing further international collaborations. The names of these sections are: (1) Preferences for developing research capacity; (2) Involvement with environmental education research; (3) International collaboration; and (4) Background information.

From December 2017 to January 2018, each of our group members personally solicited around 15 participants who are engaging EE research in the each country and obtained the consent for their participation in this pilot survey. Duration of data collection was from the end of December to the end of January 2018. Before proceeding to the questions, participants are requested to read the definition of "research" to confirm whether he or she is taking any part of it.

\section{Results}

\section{Overall trends}

Our sample is the total of 51 participants, consisting of Japanese $(n=15)$, Korean $(n=20)$ and Taiwanese $(n=12)$ nationalities, and 4 of them skipped the question. Most of the participants are working at higher educational institutions $(53 \%)$ and research institutions (15\%), and few of them are graduate students. With regard to gender ratio, almost $47 \%$ are male, and $51 \%$ are female. The majority of respondents are researchers at the early to mid 
stages of their career: almost $74 \%$ are 50 years old or younger; $66 \%$ work less than 15 years after graduation; and $23 \%$ hold a Master's degree, $60 \%$ hold a doctorate. $43 \%$ of the respondents stated to have studied abroad. Few of them are graduate students. The proportion of participants based on the number of year engaging in research is shown in Table 1. The entire result can be accessed from the QR code on the right side and the web address below (Figure 1).

Table 1 Participant engagement in research by years and nation (\# of respondents)

\begin{tabular}{llllllll}
\hline & $<5$ years & $\begin{array}{l}6 \text { to } 10 \\
\text { years }\end{array}$ & $\begin{array}{l}11 \text { to } 15 \\
\text { years }\end{array}$ & $\begin{array}{l}16 \text { to } 20 \\
\text { years }\end{array}$ & $>20$ years & Total \\
\hline Japanese & $26.7 \%(4)$ & $26.7 \%(4)$ & $26.7 \%(4)$ & $13.3 \%(2)$ & $6.7 \%(1)$ & $31.9 \%(15)$ \\
Korean & $5 \%(1)$ & $20 \%(4)$ & $35 \%(7)$ & $20 \%(4)$ & $20 \%(4)$ & $42.5 \%(20)$ \\
Taiwanese & $16.7 \%(2)$ & $33.3 \%(4)$ & $8.3 \%(1)$ & $8.3 \%(1)$ & $33.3 \%(4)$ & $25.5 \%(12)$ \\
Total & 7 & 12 & 12 & 7 & 9 & 47 \\
\hline
\end{tabular}

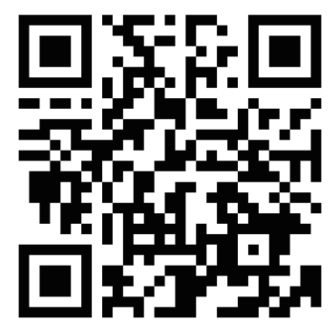

Figure 1

QR Code for the entire result

As for academic commitment to EE, the majority of our sample (57\%) deals with EE as his/her primary research field, and $41 \%$ are committed to EE as one of his/her important fields. Regarding the research sectors in which the respondents mainly involve (Q9), K-12 formal education (48\%), teacher education in formal education (33\%) and non-formal education in local community (33\%) are studied most (Table 2). As for thematic topics (Q10), Education for sustainable development (ESD) (63\%), sustainable development, sustainability and/or Sustainable Development Goals (SDGs) (38\%), community development (27\%) are being studied most (Table 3).

2. Capacity building

Table 2 Popular research sectors (Q9)

\begin{tabular}{ll}
\hline Educational sector & $\begin{array}{l}\text { \% of responses } \\
\text { (\# of respondents) }\end{array}$ \\
\hline (1) Formal education (K-12) & $47.92 \%(23)$ \\
(2) Formal education (teacher education), & $33.33 \%(16)$ \\
$\quad$ Non-formal education (local community, & $33.33 \%(16)$ \\
$\quad$ company property and/or other types) & $31.25 \%(15)$ \\
(3) Formal education (Env. Studies, science at & \\
$\quad$ higher education) & $22.92 \%(11)$ \\
(4) Non-formal education (Nature/Env. Centers) & $12.5 \%(6)$ \\
(5) Formal education (Other higher education) &
\end{tabular}

Table 3 EE thematic discourse emphasis (Q10)

\begin{tabular}{ll}
\hline Thematic area & $\begin{array}{l}\% \text { of responses } \\
\text { (\# of respondents) }\end{array}$ \\
\hline (1) ESD & $62.5 \%(30)$ \\
(2) Sustainable development, sustainability & $37.5 \%(18)$ \\
and/or SDGs & \\
(3) Community development & $27.1 \%(13)$ \\
(4) Climate change & $20.8 \%(10)$ \\
(5) Curriculum development & $18.8 \%(9)$ \\
\hline
\end{tabular}

In our pilot survey, we provided several questions concerning researchers' interests in capacity building opportunities (Q3 to Q7). Participants were asked to evaluate their research skills (Q3) on a Likert scale according to the categories of (1) very weak, (2) weak, (3) average, (4) strong, and (5) very strong. Based on the weighted average ranging

Figure 1: The preview of the pilot survey is shown at:

www.surveymonkey.net/r/Preview/?sm=aDwKCmfnMJIgpP9nPd1xtcO7y3b7WnTU5EbHPna9MkpEiZ 2FIQIRjBZZbyMDkYd60

The result is also shown at: www.surveymonkey.com/results/SM-SZ36ZHCTV/ 
from 1 to 5 points, Table 4 shows the five strongest and weakest research skills accordingly. The highest three were "generating a research idea" (3.73), "developing research proposals" (3.65), and "collecting data/negotiating access to participants" (3.55), whereas the three weakest research skills resulted "sharing research findings with international audiences" (2.79), "designing international comparative research" (2.82), and "designing quantitative research" (3.00).

Table 4 Self-evaluation of research skills (Strong and weak areas)

\begin{tabular}{llll}
\hline & & Area of research skills & $\begin{array}{l}\text { Ave. Point } \\
(1-5)\end{array}$ \\
\hline Research skills & (1) & Generating a research idea & 3.73 \\
(Strong) & $(2)$ & Developing research proposals & 3.65 \\
& (3) & Collecting data/negotiating access to participants & 3.55 \\
& (4) & Orally presenting research, and conducting a literature review & 3.53 \\
& (5) & Designing qualitative research & 3.49 \\
\hline Research skills & (1) & Quantitative data analysis & 3.04 \\
(Weak) & $(2)$ & Conducting a literature review in international context & 3.02 \\
& (3) & Designing quantitative research & 3.00 \\
& (4) & Designing international comparative research & 2.82 \\
& (5) & Sharing research findings with international audiences & 2.79 \\
\hline
\end{tabular}

Regarding his/her training opportunities, slightly more than the half of respondents (53\%) participated in some sort of training/education opportunities since finishing his/her highest degree, and the type varies from visiting scholarship to short seminar during academic conferences. The great majority of respondents (90\%) are interested in participating in training opportunities to improve their research skills. Among those respondents, the highest interest is shown in the topics of quantitative data analysis (48.89\%) and quantitative research design (37.78\%) whereas the interest in qualitative research designing is slightly lower (Table 5). With regard to methodology (Q6), case studies $(62.50 \%)$ and interviews $(52.08 \%)$ are used most frequently(Table 6).

\section{International collaboration}

Table 5 Areas for increasing research skill

\begin{tabular}{lrll}
\hline & & Area of research skills & $\begin{array}{c}\text { \% of responses } \\
\text { (\# of respondents) }\end{array}$ \\
\hline Training areas interested & (1) & Quantitative data analysis & $48.89 \%(22)$ \\
& $(2)$ & Quantitative research design & $37.78 \%(17)$ \\
& $(3)$ & Qualitative research design & $33.33 \%(15)$ \\
& (4) Applying for funding, & $28.89 \%(13)$ \\
& & Qualitative data analysis, & $28.89 \%(13)$ \\
& & Publishing research & $28.89 \%(13)$ \\
& (5) Designing international comparative research & $26.67 \%(12)$ \\
\hline
\end{tabular}

Table 6 Popular research designs used

\begin{tabular}{llll}
\hline & & Method type & $\begin{array}{l}\% \text { of responses } \\
\text { (\# of respondents) }\end{array}$ \\
\hline Popular research & (1) & Case studies & $62.50 \%(30)$ \\
designs used & $(2)$ & Interviews & $52.08 \%(25)$ \\
& $(3)$ & Survey & $35.42 \%(17)$ \\
& (4) & Mixed method research, & $31.25 \%(15)$ \\
& & Text-based approach to & $31.25 \%(15)$ \\
& & qualitative research \\
& (5) & Action research & $29.17 \%(14)$ \\
\hline
\end{tabular}

As expected, the respondent interest in taking part in international collaboration is high (Q17). Within the total of $96 \%, 44 \%$ expressed strong interest while $52 \%$ indicating ordinal interest in participating some level of international collaboration. On the other hand, the majority of respondents $(65 \%)$ selected that their institutions have a higher 
interest in the internationalization of research activities (Q18). As for the area of international collaboration, "sharing information about the latest research findings" (50\%), "designing and conducting international comparative studies" (48\%) and "starting a new research project" (39\%), were most selected. Participants were asked to rate the levels of education preferred for international collaboration on a Likert scale according to the categories of (1) disagree, (2) slightly disagree, (3) neither option, (4) slightly agree, and (5) agree (Q21). According to the weighted average ranging from 0 to 5 points, the highest five points were in non-formal education in nature/EE centers (2.62), nonformal education in local community (2.59), formal education in teacher education (2.55), formal education in adult, continuing and extension education (2.45), and non-formal education in national and international sites (2.45) (Table 7). With regard to thematic areas preferred for international collaboration, participants were asked to rate their level of interest according to the categories of (1) no interest, (2) neutral, (3) I am interested, and (4) N/A. Among 27 choices, the five most popular thematic areas were "ESD," "sustainable development/sustainability and/or SDGs," "community development," "social change," and "curriculum development" (Table 8).

\section{Table 7 Preferred research in education levels}

\begin{tabular}{|c|c|c|c|}
\hline & & Educational sector & $\begin{array}{l}\text { Ave. Point } \\
(1-5)\end{array}$ \\
\hline \multirow[t]{6}{*}{ Levels interested } & (1) & Non-formal education (Nature/EE centers) & 2.62 \\
\hline & (2) & $\begin{array}{l}\text { Non-formal education in local community, } \\
\text { company property and/or other types }\end{array}$ & 2.59 \\
\hline & (3) & Formal education (Teacher Education) & 2.55 \\
\hline & (4) & $\begin{array}{l}\text { Formal education (Adult, continuing and } \\
\text { extension Ed), }\end{array}$ & 2.45 \\
\hline & & $\begin{array}{l}\text { Non-formal education (National and } \\
\text { international sites) }\end{array}$ & 2.45 \\
\hline & (5) & Formal Education (Other higher education) & 2.43 \\
\hline
\end{tabular}

Table 8 Preferred thematic areas for international collaboration

\begin{tabular}{llll}
\hline & \multicolumn{1}{c}{ Thematic area } & $\begin{array}{l}\% \text { of responses } \\
\text { (\# of respondents) }\end{array}$ \\
\hline $\begin{array}{l}\text { Thematic areas } \\
\text { interested }\end{array}$ & (1) & ESD & $79.6 \%(35)$ \\
& (2) & Sustainable development/sustainability & $77.8 \%(35)$ \\
& & and/or SDGs & \\
& (3) & Community development, & $65.9 \%(29)$ \\
& (4) Social change & $65.9 \%(29)$ \\
& (5) Curriculum development & $64.4 \%(29)$ \\
\hline
\end{tabular}

\section{Conclusion}

In spite of the sample participant size, the pilot survey substantiated some notable trends that can be taken into account when designing a future comparative survey. The trends to be acknowledged and emphasized include: (1) the strong interest in training opportunities and international collaboration; (2) the high interest in ESD, SDGs and sustainability discourses; (3) a set of thematic interests in and tactical barriers against international collaboration. Also, as shown in Table 4, the lack of confidence in particular research skills and the popularity in case study and interview research design appear to indicate the potential needs for providing capacity building opportunities. Regarding the questionnaire revision, it is obvious that the questions dealing with ESD and sustainability discourses like SDGs need to be refined for obtaining more tangible tendencies that would help to identify potential areas for international collaboration. This task requires further discussion and research.

Toward conducting a larger-scale survey, two aspects should be stressed. First, use of native language is essential to securing greater participants. This would improve the accuracy of meaning sometimes lost through translation and increase the efficiency of completion. More survey participants would enable us to conduct cross-national comparisons, which this study could not. Second, the support from the participating academic societies is crucial not only for executing a full-scale survey but also facilitating opportunities for increasing research skills and capacities 
concerning international collaboration. Such supports can be made based upon the exchange agreements between the Japanese Society for Environmental Education and EE societies/associations abroad (Ninomiya-Lim et al, 2017). A number of possible support areas on how the research capacity could be developed, such as providing research training, increasing access to funding, incentivizing international research, coordinating international research, promoting international collaboration, and disseminating research. This in turn would further contribute to the momentum for nurturing "greater openness to new cultures" in the field of EE.

\section{References}

Altbach, G.P. 1996. The international academic profession: Portraits of fourteen countries. San Francisco, CA: The Carnegie Foundation for the Advancement of Teaching.

Ardoin, N.M., Clark, C., and Kelsey, E. 2013. An exploration of future trends in environmental education research. Environmental Education Research. 19(4):499-520.

Callicott, J.B., and James M. (Eds). 2014. Environmental Philosophy in Asian Traditions of Thought. Albany: State University of New York.

Chen, K.-H. 2010. Asia as Method: Toward Deimperialization. Durham, North Carolina: Duke University Press.

Dillon, J., and Wals, A.E. 2006. On the dangers of blurring methods, methodologies and ideologies in environmental education research. Environmental Education Research. 12(3/4):549-558.

Erdogan, M., Marcinkowski, T., and Ok, A. 2009. Content analysis of K-8 environmental education research studies in Turkey, 1997-2007. Environmental Education Research. 15(5):525-548.

Gough, A. 2013. The emergence of environmental education research. In International Handbook of Research on Environmental Education, edited by Stevenson, R.B. et al., 13-23. New York: Routledge.

Gough, N. 2013. Thinking Globally in Environmental Education. In International Handbook of Research on Environmental Education, edited by Stevenson, R.B. et al., 33-44. New York: Routledge.

Hesselink, F., van Kempen, P.P, and Wals, A. (Eds). 2000. ESDebate International debate on education for sustainable development. Gland: IUCN.

Jackson, L. 2017. 'Asian' Perspectives on Education for Sustainable Development. Educational Philosophy and Theory. 49(5):473-479.

Kim, C. 2017. Research Trends in Environmental Education of Korea: The Past, Present, and Future. Japanese Journal of Environmental Education. 26(4):45-50.

Marcinkowski, T., Bucheit, J., Spero, V., Linsenbardt, C., Engelhardt, J., Stadel, M., Santangelo, R., and Guzmon, K. 2013. Selected trends in thirty years of doctoral research in environmental education in Dissertation Abstracts International from collections prepared in the U.S. In International Handbook of Research on Environmental Education, edited by Stevenson, R.B. et al., 45-62. New York: Routledge.

McHugh, P., and Byrne, M. 2014. Survey of the research activity, skills and training needs of Health and Social Care Professionals (HSCPs) in Ireland 2013. Health Service Executive (HSE). Dublin

Mielke, J., Vermaßen, H., and Ellenbeck, S. 2017. Ideals, practices, and future prospects of stakeholder involvement in sustainability science. Proceedings of the National Academy of Sciences. 114 E10648-E10657.

Miike, Y. 2016. Asian communication studies at the crossroads- A view to the future from an Asiacentric framework. Journal of Content, Community and Communication. 3(2):1-6.

Ninomiya-Lim, S., Sakurai, R., Kim, C., Chang, T., Lee, S., and Furihata, S. 2017. Sharing, Comparing, and Developing Environmental Education in Asia: For the Journey to be Continued. Japanese Journal of Environmental Education. 26(4):77-83.

Nomura, K. 2017. Environmental Education Research in Japan -A Fragmented Field of Inquiry-. Japanese Journal of Environmental Education. 26(4):57-64.

Park, J. 2017. Knowledge Production with Asia-Centric Research Methodology. Comparative Education Review. 61(4):760-779.

Reid, A., and Scott, W. 2006. Researching education and the environment: Retrospect and prospect. Environmental Education Research. 12(3-4):571-587. 
Reunamo, J., and Pipere, A. 2011. Doing research on education for sustainable development. International Journal of Sustainability in Higher Education. 12(2):110-124.

Sauvé, L. 2005. Currents in environmental education- Mapping a complex and evolving. Canadian Journal of Environmental Education. 10(1):11-37.

Scott, W. 2009. Environmental education research: 30 years on from Tbilisi. Environmental Education Research. 15(2):155-164.

Stevenson, R.B., and Evans, N. 2011. The distinctive characteristics of environmental education research in Australia: An historical and comparative analysis. Australian Journal of Environmental Education. 27(1):24-45.

Takayama, K., Sriprakash, A., and Connell, R. 2017. Toward a postcolonial comparative and international education. Comparative Education Review. 61(S1):S1-S24.

Yonezawa, A., Kitamura, Y., Meerman, A., and Kuroda, K. Eds. 2014. Emerging international dimensions in East Asian higher education. Springer Science \& Business Media. New York. 